\title{
GOOD NEWS FOR DEMATEL USERS: THE ORIGINAL POTENTIAL OF THE METHOD IS STILL AWAITING FULL EXPLOITATION
}

\section{Grzegorz Ginda}

\author{
Faculty of Management, AGH UST, ul. Gramatyka 10, Cracow, Poland \\ E-mail: gginda@zarz.agh.edu.pl
}

Received 06 March 2020; accepted 07 May 2020

\begin{abstract}
DEMATEL technique is almost 50 years old. A long history of its application to solve diverse problems from different fields has provided diverse improvements to the technique to make it even more powerful. It nevertheless seems that some original merits of the technique were accidentally lost, as well. The merits proved to be very useful for a complex and comprehensive research made by DEMATEL inventors. So, it seems that they could also prove useful for contemporary researchers. This why an effort is made in the paper to recall and describe these merits and assess their usefulness for supporting a comprehensive decision analysis today.
\end{abstract}

Keywords: DEMATEL, original, potential, application, decision, analysis, support.

JEL Classification: C65.

\section{Introduction}

DEMATEL technique has been developed rather a long time ago. The original purpose of the technique was the identification of the structure of contemporary world's problems. The technique was invented during actual realization of a research project at the Batelle Memorial Institute, Geneva, Switzerland in the early 1970s by the team led by two researchers, namely Emilio Fontela and André Gabus. The technique has been invented particularly for the implementation research project was called DEcision MAking Trial and Evaluation Laboratory of the Science and Human Affairs Program of the Batelle Memorial Institute (Fontela \& Gabus, 1973).

DEMATEL technique became particularly popular in the beginning of the $21^{\text {st }}$ century (see: Figure 1). It has been utilized since then for solving numerous problems in diverse areas (see: Figure 2), and diverse purposes (Sheng-Li et al., 2018; Kawata, 1981; Furumoto et al., 1998; Hori \& Shimizu, 1999; Ren et al., 2001; Fukushi \& Narita, 2002; Tamura \& Akazawa, 2005; Chiu et al., 2006; Wu \& Lee, 2007; Liou et al., 2008; Dytczak \& Ginda, 2009, 2013; Lee et al., 2010; Jerry Ho et al., 2011; Wu et al., 2012; Lee, 2013; Tan \& Kuo, 2014; Qu et al., 2015; Lin et al., 2016; Zhou et al., 2017; Chen et al., 2018; Torbacki \& Kijewska, 2019; Jayakrishna et al., 2020). The main reason for the great popularity of the technique results from its capability to provide means for the effective identification of causeeffect chains despite the availability of rather scarce information about influence of objects that comprise a considered system.

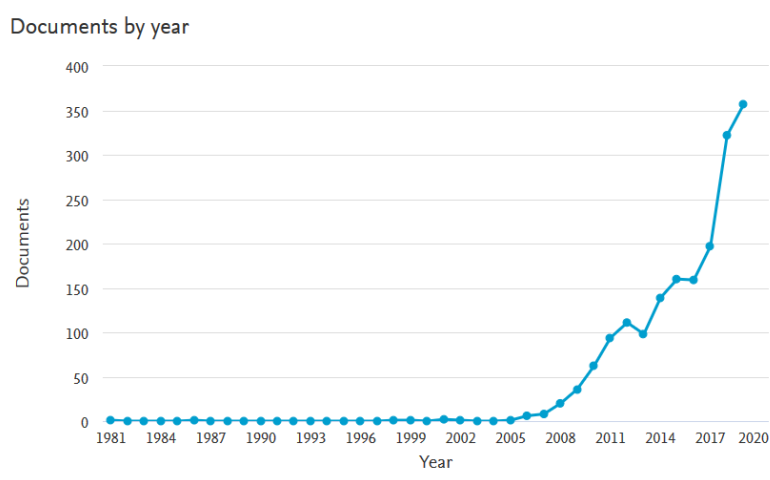

Figure 1. Yearly rate of DEMATEL-related publications (source: http://www.scopus.com)

Typical DEMATEL application exploits the basic procedure which consists of the following steps. The first step deals with the definition of a structure of direct influence of components of a given system on each other. Note that actual notion of direct influence results from actual needs of analysis, namely: character of considered system, its components and interactions between them, etc. Levels of an ordinal scale are utilized to express direct influence of system components. The scale always consists of level 0, which expresses a lack of direct influence, and level $N$, which pertains to the extreme possible direct influence. The intermediate scale lev- 
els, from 1 to $N-1$, denote increasing direct influence intensity. Original DEMATEL scale consists of 5 levels which are expressed by consecutive integers: $0,1,2,3$, and $N=4$. Note that the assessmentof direct influence intensity may be provided by $K$ different experts. Each expert delivers a set of assessments which corresponds with his view of a structure of direct influence. The structure covers direction and intensity of direct influence of $n$ components of a considered system on each other. The consecutive system components may be associated with subsequent rows and columns of a quadratic $n$ by $n$ matrix of direct influence $\mathbf{X}^{*(k)}$. The element $x_{i j}{ }^{*}(k)$ of the matrix corresponds with possible direct influence of the $\mathrm{i}$-th consecutive system component on the $\mathrm{j}$-th consecutive system component, according to the k-th consecutive expert:

$$
\underset{k=1 \ldots K}{\forall} \mathbf{X}^{*(k)}=\left[x_{i j}^{*(k)}\right]_{n \times n} .
$$

Note that a digraph of direct influence, which corresponds with matrix (1) may be also applied to express and visualize structure of direct influence. Nodes of the digraph correspond to system components while weighted arcs express possible direct impact of the components on the remaining system components.

Documents by subject area

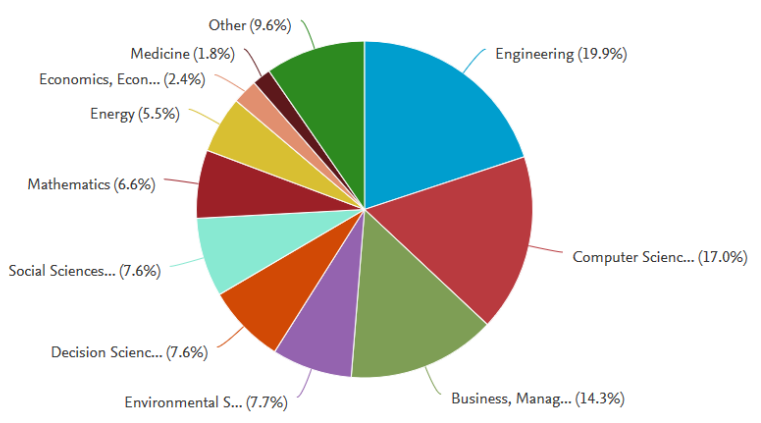

Figure 2. Diversity of DEMATEL application areas (source: http://www.scopus.com)

The second step of the procedure results in average direct influence structure. The structure is expressed by a quadratic $n$ by $n$ matrix $\mathbf{X}^{*}$ :

$$
\mathbf{X}^{*}=\frac{\sum_{k=1}^{K} \mathbf{X}^{*(k)}}{K} .
$$

The third step is devoted to deriving adequate form $\mathbf{X}$ of matrix (2) that satisfies the following condition:

$$
\mathbf{X}^{*} \rightarrow \mathbf{X}: \lim _{m \rightarrow \infty} \mathbf{X}^{m}=\mathbf{0}_{n \times n} .
$$

The structure of total influence covers both direct $\mathbf{X}$ and indirect influence $\mathbf{\Delta} \mathbf{X}$ of system components. It is represented by a quadratic $n$ by $n$ matrix of total influence $\mathbf{T}$ :

$$
\mathbf{T}=\mathbf{X}+\Delta \mathbf{X} .
$$

The adeqaute form of direct influence matrix $\mathbf{X}$ (3) allows to derive structure of total influence thanks to the following formula:

$$
\mathbf{T}=\mathbf{X}(\mathbf{I}-\mathbf{X})^{-1},
$$

where $\mathbf{I}$ denotes an $n$ by $n$ identity matrix.

The element $t_{i j}$ of the matrix expresses total influence of the $\mathrm{i}$-th consecutive system component on the $\mathrm{j}$-th consecutive system component. Note that a structure of total influence may be also expressed by a digraph of total influence which corresponds with matrix $\mathbf{T}$ contents.

Matrix T makes it possible to compute two indices $(6,7)$ for the i-th consecutive system component:

$$
\begin{gathered}
\underset{\substack{i=1 \ldots n \\
\forall}}{\forall} s_{i}^{+}=\sum_{j=1}^{n}\left(t_{i j}+t_{j i}\right), \\
\underset{i=1 \ldots n}{\forall} \quad s_{i}^{-}=\sum_{j=1}^{n}\left(t_{i j}-t_{j i}\right) .
\end{gathered}
$$

The first index (6) is called the prominence. It is used to express overall significance of the $\mathrm{i}$-th consecutive system component. Note that it is based on the sum of matrix $\mathbf{T}$ elements in the $\mathrm{i}$-th consecutive row and the $\mathrm{i}$-th consecutive column. Note that the higher value of $s^{+}{ }_{i}$ is, the more siginficant the $\mathrm{i}$-th consecutive system omponent is. The second index (7) is called the relation. It is used to express role of the $\mathrm{i}$-th consecutive system component. Note that the higher the positive value of the index is, the more causal the $i$-th consecutive system element is. On the other hand, the lower the negative value of the relation is, the more certain effect the $i$-th consecutive system component is.

It proves out, however, that the technique actually provides more interesting features than just the effective identification of cause-effect chains. This is because original reports about the technique (Fontela \& Gabus, 1973; Fontela, 1974; Gabus, 1974; Fontela, \& Gabus, 1975; Gabus \& Fontela, 1975; Gabus \& Fontela, 1976), which have been provided by DEMATEL inventors, namely: Emilio Fontela and André Gabus, indicated many more interesting features of the technique which seem not to be recognized by contemporary technique users. It seems that this is mainly due to actual unavability of original information about the technique. Indeed, several orig- 
inal reports became available to Internet users in early years of the $21^{\text {st }}$ century when the general interest in the technique was only starting to grow, and it left the majority, particularly new, DEMATEL users unaware of some interesting features of the technique. The presentation of forgotten ideas behind the original technique proposal becomes purposeful, therefore. This is why they are presented in the paper.

The paper is structured as follows. Results of original DEMATEL application are used in the paper to illustrate its forgotten features. This is why a background of original version of technique development is presented in the second section. The third section is devoted to the forgotten features themselves. Final conclusions with regard to the possible contemporary usefulness of the features are drawn in the final section.

\section{DEMATEL origin background}

A block scheme of complete procedure of original DEMATEL is presented in Figure 3. It is obvious that there are three fundamental differences between original proposal of Fontela and Gabus as well as the commonly known and used form of the technique, which was discussed in section 1 .

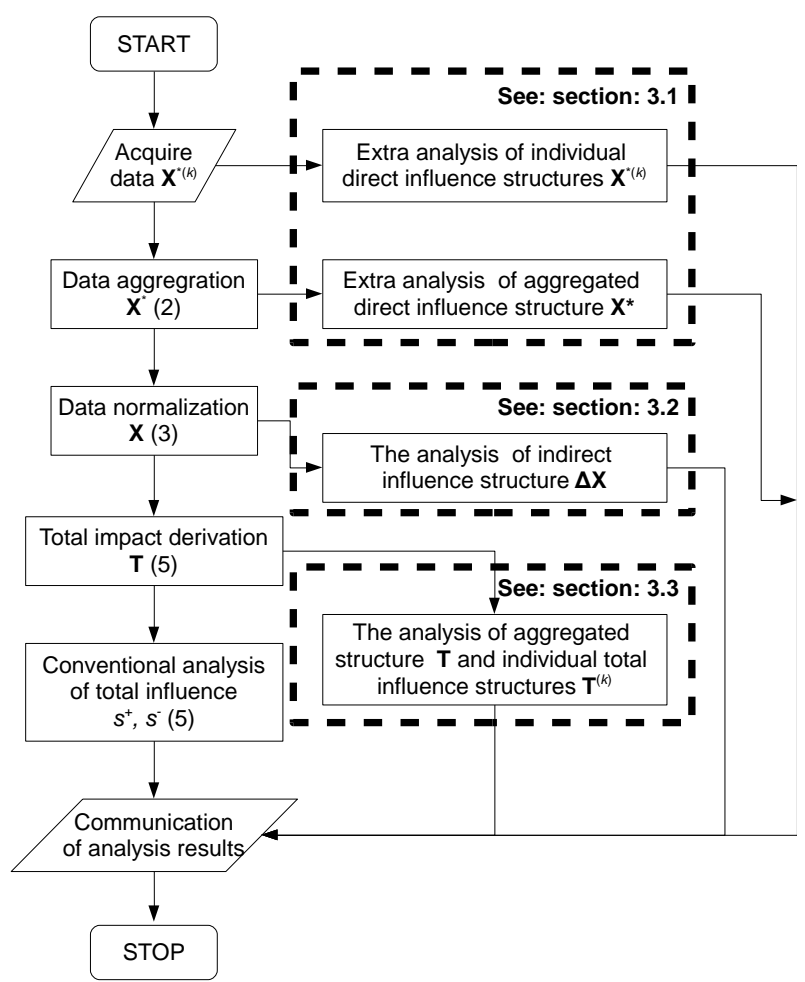

Figure 3. Complete original DEMATEL scheme (source: http://www.scopus.com)

The first fundamental difference deals with the possibility of analysis of individual direct influence structures provided by distinct experts $\mathbf{X}^{*(k)}$ and aver- age direct influence structure $\mathbf{X}^{*}$. The second fundamental dfference pertains to the analysis of indirect influence structure $\boldsymbol{\Delta} \mathbf{X}$ while the last fundamental difference is related to enhancements of total influence structure analysis.

A system which was originally analyzed during the implementation of original DEMATEL project by Fontela and Gabus (1973) is used in a paper to present original features of the technique. The system dealt with 48 contemporary world's problems of the early 1970s. The problems covered both global world issues as well as regional issues. They were divided in 14 thematic groups A-N which covered (note the original spelling) (Gabus \& Fontela, 1976):

- theme A - obstacles to world organistation: inadequacy of the institutional organizations of international society $(i=1)$, the difficulty experienced by major powers in defining their interests and responsibility $(i=2)$, the arms race $(i=3)$, and inadequate regulation of use of the sea $(i=4)$,

- theme B - infringement of the rights of nations: intereference by foreign powers $(i=$ $5)$, interference by mutinational companies $(i=6)$, and non-completion of decolonisation $(i=7)$,

- theme C - inefectiveness of inbstitutions: inability of institutions to adapt to external cange $(i=8)$, political instability, particularly in the less-developed countries LDCs $(i=9)$, insufficient personal involvement in political and economic life $(i=10)$,

- theme D - difficulties in improving the standard of leaving in rapidly growing population: disproportion between active and inactive population $(i=11)$, maladaptation of urban concentration to individual and collective needs $(i=12)$, poor use of available land $(i=13)$,

- theme E - the crisis of advanced industrial societes: physical and mental illnesses characteristics of advanced industrial civilisation $(i=14)$, loss of the sense of personal security $(i=15)$, obstacles to fulfilment of of non-material aspirations $(i=$ 16),

- theme F - social discrimination: racial discrimination $(i=17)$, recurring threads to the existence of minorities $(i=18)$, social discrimination based on sex $(i=19)$,

- theme $\mathrm{G}$ - the use of violence: physical violence in political and social conflicts $(i=20)$, infringements of fundamental per- 
sonal freedoms $(i=21)$, increase in criminality and delinquency $(i=22)$, hijacking and sabotage of aircraft $(i=23)$,

- theme $\mathrm{H}$ - shortcomings in education and communication: communication difficulties due to complexity and multiplicity of jargon and languages $(i=24)$, intensification of political, economic and cultural propaganda in association with the development of mass media $(i=25)$, insufficient education of children and adults for active life $(i=26)$,

- theme I - the weakening of human motivations: weakening of collective convictions (social, religious, etc.) $(i=27)$, difficulkties of social advancement $(i=28)$, acute disparities between living conditions and aspirations $(i=29)$, production, traffic and use of drugs $(i=30)$,

- theme $\mathbf{J}$ - degradation and disfigurement of the environment: lasting damage to vital properties of water $(i=31)$, damage (including noise) to the properties of atmosphere $(i=32)$, damage to vital properties of the soil $(i=33)$, disfigurement of environment: destruction of cultural monuments, natural beauties, etc. $(i=34)$, attacks on man's genetic heritage $(i=35)$,

- theme $\mathrm{K}$ - shortcomings in production and technology: wastage and underemployment of human resources $(i=36)$, fundamental waste of material and financial resources $(i=37)$, exhaustion of nonrenewable mineral and energy reserves $(i=38)$, inadequate bcontrol of technological development $(i=39)$, and insufficent efforts to anticipate the exhastion of energy reserve and to produce less pollutant energy $(i=40)$,

- theme L - monetary instability: difficulty in checking inflation $(i=41)$ and crises in the international monetary system $(i=42)$,

- theme M - obstacles to international economic relations: lack of capital for aid to LDCs $(i=43)$, low and fluctuating prices of exports from LDCs $(i=44)$, and changes in the flow of international trade due to establishment of preferential areas $(i=45)$,

- theme $\mathrm{N}$ - failure to satify basic needs of the LDCs: undernutrition and malnutrition in the LDCs $(i=46)$, endemic and epidemic disease in the LDCs $(i=47)$, and housing shortages and deficiencies in LDCs $(i=48)$.
A survey research was applied to gain opinions of influential persons who represented different continents, countries, professions and positions (Gabus, 1974) - see: Table 1 and Table 2 with this regard. The survey research dealt with qestions about direct influence of problems on each other. The respondents of the survey were provided with feedback about consequences of their own opinions to facilitate rethining their opinions. A total of $K=32$ complete direct problem influence structures were obtained from the respondents. These structures were finally processed by means of original DEMATEL technique.

Table 1. Repondents' characteristics (source: Gabus \& Fontela, 1976)

\begin{tabular}{|l|l|l|}
\hline \multicolumn{1}{|c|}{ Function } & \multicolumn{1}{|c|}{ Codes } & Quantity \\
\hline \multicolumn{2}{|l|}{ Administration } & $\mathbf{1 1}$ \\
\hline $\begin{array}{l}\text { Prime Minister's del- } \\
\text { egates / advisors }\end{array}$ & $\begin{array}{l}003,006,111,112, \\
132\end{array}$ & 5 \\
\hline Ministers & $108,126,128$ & 3 \\
\hline $\begin{array}{l}\text { High official in public } \\
\text { administration }\end{array}$ & 110,135 & 21 \\
\hline $\begin{array}{l}\text { High official in inter- } \\
\text { national organisation }\end{array}$ & 117 & 1 \\
\hline Opinion makers / business & $\mathbf{1 2}$ \\
\hline Trade union leaders & 123,124 & 2 \\
\hline $\begin{array}{l}\text { Political party repre- } \\
\text { sentatives }\end{array}$ & 133,134 & 2 \\
\hline Senators & 004,119 & 2 \\
\hline Editorialists & 107,113 & 2 \\
\hline Corporate directors & $116,122,125,129$ & 4 \\
\hline Other influential persons & $\mathbf{9}$ \\
\hline University professors & $101,105,118$ & 3 \\
\hline Scientific researchers & $005,106,121$ & 3 \\
\hline $\begin{array}{l}\text { Religion representa- } \\
\text { tives }\end{array}$ & $007,104,127$ & 3 \\
\hline
\end{tabular}

\section{Less known features of original DEMATEL}

\subsection{Extra analysis of direct influence}

Fontela (1974) proposed several enhancements to the analysis of direct problem influence. The first one pertains to the identification of general influential and consequent character of a distinct problem. The application of adequate row-wise (8) and column-wise (9) sum of average direct influence matrix $\mathbf{X}^{*}$ was proposed with this regard to measure direct impact of the i-th consecutive problem on the remainning problems and to measure direct impact of the remaining problems on the problem, respectively: 


$$
\begin{array}{cc}
\underset{i=1 \ldots n}{\forall} & \sum_{j=1}^{n} x_{i j}^{*}, \\
\underset{i=1 \ldots n}{\forall} & \sum_{j=1}^{n} x_{j i}^{*} .
\end{array}
$$

According to DEMATEL inventors similar analysis could be conducted in the case of direct structures provided by distinct experts:

$$
\begin{gathered}
\underset{k=1 \ldots K}{\forall} \underset{j=1 \ldots n}{\forall} \sum_{j=1}^{n} x_{i j}^{*(k)}, \\
\underset{k=1 \ldots K}{\forall} \underset{i=1 \ldots n}{\forall} \sum_{j=1}^{\forall} x_{j i}^{*(k)} .
\end{gathered}
$$

The application of formulae (8-10) could undoubtedly facilitate the identification of the most influential as well as the least influential problems.

Table 2. Geograpohical origin of the respondents (source: Gabus \& Fontela, 1976)

\begin{tabular}{|l|c|}
\hline \multicolumn{1}{|c|}{ Country } & Quantity \\
\hline Developed countries & $\mathbf{2 7}$ \\
\hline Europe & $\mathbf{1 3}$ \\
\hline Austria & 1 \\
\hline France & 7 \\
\hline Italy & 1 \\
\hline Spain & 1 \\
\hline Switzerland & 3 \\
\hline North America & $\mathbf{9}$ \\
\hline Canada & 1 \\
\hline United States of America & 8 \\
\hline Japan & $\mathbf{5}$ \\
\hline LDCs & $\mathbf{5}$ \\
\hline Brazil, India, Ivory Coast, Senegal, Thailand \\
\hline
\end{tabular}

The second direct influence-related analysis enhancement pertained to the analysis of general perception of problems by engaged experts. Average direct influence structure $\mathbf{X}^{*}$ was proposed to be used with this regard. The analysis provided information about the strongest direct influences of problems (see Table 3).

DEMATEL inventors also suggested to use graphical illustration of a direct influence structure of direct influence $\mathbf{X}^{*}$ to facilitate overall perception of problems. They noticed, however, that due to a significant number of possible direct problem influences, actual number of shown direct influences to had to be limited to the strongest impacts only to make the illustration of direct influence structure clear enough. This was why they finally neglected average direct impact lower than 2.0 when presenting structure of direct influence shown in Figure 4.

Table 3. Sample results of general problem perception analysis (source: Gabus \& Fontela, 1976)

\begin{tabular}{|c|c|l|c|l|c|}
\hline Rank & $i$ & Influencer & $j$ & Influenced & $x_{i j}^{*}$ \\
\hline 1 & 41 & Inflation & 42 & $\begin{array}{l}\text { Monetary } \\
\text { system }\end{array}$ & 3.312 \\
\hline 2 & 43 & $\begin{array}{l}\text { Insufficient } \\
\text { capital }\end{array}$ & 36 & HR waste & 2.969 \\
\hline 3 & 46 & $\begin{array}{l}\text { Insufficient } \\
\text { nutrition }\end{array}$ & 47 & $\begin{array}{l}\text { High } \\
\text { prevalence }\end{array}$ & 2.937 \\
\hline 4 & 14 & $\begin{array}{l}\text { Civilization } \\
\text { diseases }\end{array}$ & 15 & $\begin{array}{l}\text { No sense } \\
\text { of security }\end{array}$ & 2.781 \\
\hline 5 & 17 & Racism & 18 & $\begin{array}{l}\text { Minority } \\
\text { situation }\end{array}$ & 2.750 \\
\hline
\end{tabular}

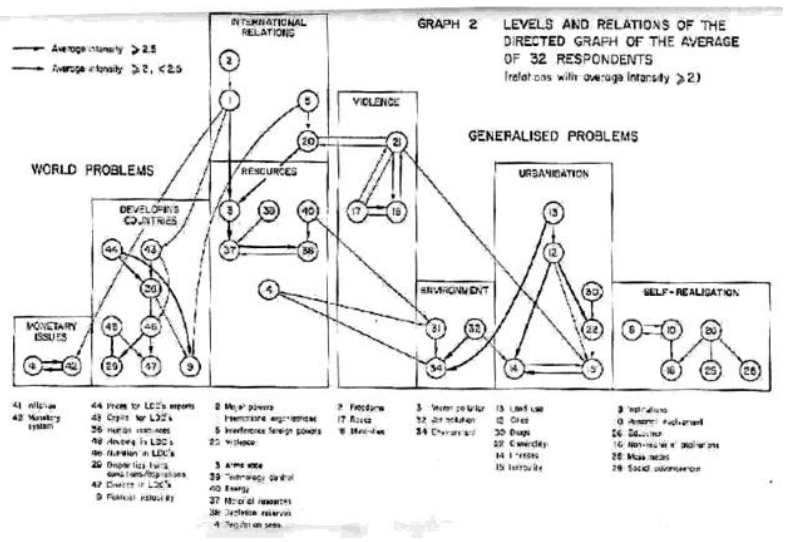

Figure 4. Sample results of original DEMATEL research project (source: Gabus \& Fontela, 1976)

The third original DEMATEL proposal dealt with the counting of occurrences of concrete direct influence intensity cases appearing in direct influence structures $\mathbf{X}^{*}(k)$. The application of distinct matrices $\mathbf{M}_{o}$ was suggested with this regard, where parameter $o$ corresponds with a distinct direct influence level $(o=0 \ldots N)$. Element in the i-th consecutive row and the $j$-th consecutive column of matrix $\mathbf{M}_{o}$ was thus equal to the number of experts who assessed direct impact of the i-th consecutive problem on the $\mathrm{j}$-th consecutive problem as $o$, at least:

$$
\underset{i k=1 \ldots K}{\forall} \underset{i, j=1 \ldots n}{\forall} \quad x_{i j}^{*(k)} \geq o .
$$

Note that the number of the matrices is equal to number of direct influence scale levels. Thus, in the case of original DEMATEL application, 5 distinct matrices were used. The matrices were also used to identify the cases of the direct impacts, amongst direct influence structures provided by distinct ep- 
erts, which had the same direction and intensity. It is also obvious that individual rows and columns of matrices $\mathbf{M}_{o}$ refer to the causal and consequent character of individual problems, repectively. This is why the analysis of content of individual rows and columns of the matrices would allow to indicate leading problems in terns of causality or effect, too.

Original DEMATEL also provided means for the identification of direct influence feedback between problems. The application of a quadratic $n$ by $n$ binary matrix $\mathbf{E}$ (13) was proposed in this regard. The elements of the matrix made it possible to indicate the fact of the existence $\left(e_{i j}=1\right)$ or a lack $\left(e_{i j}=0\right)$ of direct impact of the $i$-th consecutive problem on the $j$-th consecutive problem:

$$
\underset{i, j=1 \ldots n}{\forall} e_{i j}=\left\{\begin{array}{cc}
1 & \text { for } x_{i j}>0, \\
0 & \text { otherwise. }
\end{array}\right.
$$

The matrix was then used to obtain another quadratic $n$ by $n$ matrix $\mathbf{F}$ :

$$
\mathbf{F}=\mathbf{E}+\mathbf{E}^{\mathrm{T}},
$$

whose elements are capable of indicating the following cases for the pair of the $i$-th consecutive problem and the $j$-th consecutive problem:

- a lack of direct impact of any problem $\left(f_{i j}=0\right)$,

- a direct impact of only one of the problems on another one $\left(f_{i j}=1\right)$,

- a feedback of direct influence $\left(f_{i j}=1\right)$.

Fontela and Gabus (1975) also proposed to use information about direct influence of problems to analyse similarity of direct structures $\mathbf{X}^{(k)}$ provided by distinct experts and difference between them. A special metric $d_{k l}^{*}$ was applied with this regard. The metric made use of a notion of a distance in n-dimensional space of problems between qualitative images of direct infuence structures provided by the $k$-th consecutive expert and the 1-consecutive expert. A quadratic $n$ by $n$ binary matrix $\mathbf{D}^{(k)}(15)$ was applied to express qualitative character of direct influence structure $\mathbf{X}^{(k)}$ provided by the $k$-th consecutive expert:

$$
\underset{k=1 \ldots K}{\forall} \underset{i, j=1 \ldots n}{\forall} \quad d_{i j}^{(k)}=\left\{\begin{array}{cc}
1 & \text { for } x_{i j}^{(k)}>0, \\
0 & \text { otherwise. }
\end{array}\right.
$$

The elements of the matrix show whether the expert recoginzess the case of direct impact of the $i$-th consecutive problem on the $j$-th consecutive problem $\left(d^{(k)} i j=1\right)$ or not $\left.\left(d^{(k)}\right)_{i j}=0\right)$.

Metric $d^{*}{ }_{k l}$ could be then defined as follows:

$$
\underset{k, l=1 \ldots K}{\forall} d_{i j}^{*(k)}=\frac{\sum_{i=1}^{n} \sum_{j=1}^{n}\left(d_{i j}^{(k)}-d_{i j}^{(k)}\right)}{n^{2}} .
$$

A lack of any difference between expert opinions on a qualitative character of direct influence structure would correspond to $d_{k l}^{*}=0$, whereas value of $d_{k l}^{*}=0$ close to 1 would mean that experts differ in opinions about direction of direct problem impact a lot.

It was obvious that $d_{k l}^{*}=0$ could be treated as means for expressing dissimilarity of expert opinions about qualitative character of direct influence structure. The complement of the metric (16) to 1 (17) was proposed, therefore, to be able to express similarity of expert opinions in a direct way:

$$
\underset{k, l=1 \ldots K}{\forall} p_{k l}^{*}=1-d_{k l}^{*} .
$$

The application of complement (17) allowed to denote a lack of any difference between expert opinions by means of $p_{k l}^{*}=1$, and total dissimilarity of the opinions by value of $p_{k l}^{*}$ close to 1 . Note that in the case of original DEMATEL project implementation, the application of metric $p_{k l}^{*}$ resulted in the indication of the most compatible experts 107 and 122, for whom the following metric value was registered: $p_{k l}^{*}=0.972$.

Another original DEMATEL idea was related to the application of metric $d_{k l}^{*}$ to create a distance matrix $\mathbf{D}$ which aggregated information about qualitative difference in direct influence structures provided by experts. A concept of average distance was finally applied to define elements of the matrix:

$$
\underset{k, l=1 \ldots K}{\forall} \bar{d}_{k l}=\sqrt{d_{k l}^{*}} .
$$

Technique inventors also proposed to use information about prevailing perceptions of problem impacts and problem character to associate the experts who shared them. For example, the analysis of matrix $\mathbf{M}_{3}$ components resulted in the conclusion that the six most common direct problem impacts were perceived as the most important by 11 out of 32 experts. Note that simlar analysis could be also conducted to associate experts who shared opinions about the most popular relationships and character of problems related to a specific issue e.g. living conditions in underdeveloped countries.

Another original proposal dealt with the possibility to analyse the degree of compliance of expert 
opinions about actual direction of direct problem impacts. This was why a quadratic $n$ by $n$ binary matrix $\mathbf{G}^{(k)}$ was applied in the case of the k-th consecutive expert. An element $g_{i j}^{(k)}$ of the matrix was utilisd to express the direction of direct impact of the $\mathrm{i}$-th consecutive problem on the $\mathrm{j}$-th consecutive problem, according the k-th consecutive expert. Thus, matrix elements $g_{i j}^{(k)}=1$ denoted that, according to $\mathrm{k}$-th the expert, the $\mathrm{i}$-th consecutive problem influenced the $\mathrm{j}$-th consecutive problem, whereas $g_{i j}^{(k)}=0$ meant no influence of the i-th consecutive problem at all:

$$
\underset{k=1 \ldots K}{\forall} \underset{i, j=1 \ldots n}{\forall} \quad g_{i j}^{(k)}=\left\{\begin{array}{cc}
1 & \text { for } x_{i j}^{(k)}>0, \\
0 & \text { otherwise. }
\end{array}\right.
$$

DEMATEL inventors noticed that the maximal number of possible disagreements between two experts was equal to number of elements of matrix $\mathbf{G}^{(k)}$ i.e. $n^{2}$. They proposed, therefore, to express the level of compliance for the k-th consecutive expert and the 1-consecutive expert by means of $\Delta g_{k l}$ indicator:

$$
\underset{k, l=1 \ldots K}{\forall} \quad \Delta g_{k l}=n^{2}-\sum_{i=1}^{n} \sum_{j=1}^{n}\left|g_{i j}^{(k)}-g_{i j}^{(l)}\right| .
$$

It was also proposed to use similar way to analyse the compliance of experts with regard to character of distinct problems. Information provided in distinct rows and columns of matrices $\mathbf{G}^{(k)}$ and $\mathbf{G}^{(l)}$ was applied in this regard. The maximal number of possible disagreements equaled to $n$ for each considered problem. Thus, the following indices, analogous to (20), were finally introduced:

$$
\begin{gathered}
\underset{k, l=1 \ldots K}{\underset{i=1 \ldots n}{\forall}} \Delta h_{i k l}^{+}=n-\sum_{j=1}^{n}\left|g_{i j}^{(k)}-g_{i j}^{(l)}\right| ; \\
\underset{k, l=1 \ldots K}{\forall} \underset{i=1 \ldots n}{\forall} \Delta h_{i k l}^{-}=n-\sum_{j=1}^{n}\left|g_{j i}^{(k)}-g_{j i}^{(l)}\right|,
\end{gathered}
$$

to express experts' compliance with regard to causal and consequent character of the i-th consecutive problem, respectively. Note that the application of indices $(21,22)$ allowed Fontela and Gabus to draw interesting conclusions during original DEMATEL project implementation. This was because it turned out that engaged experts more often agreed to causality of problems than to their consequent character.

Note that in practice, we can't expect perfect compliance of experts. This was also why DEMATEL inventors proposed to use a kind of a concordance threshold, which represened majority of possible 48 agreements. The application of the threshold which would actually allow to recognize sufficient compliance of experts' opinions. It was finally set at 33 concordant opinions which corresponded with the majority of two thirds (2/3) of possible opinions plus one. The application of the threshold allowed Fontela and Gabus to divide 22 experts, who shared the same set of opinions about character of sufficient majority of problems, into 6 groups. Two major groups consisted of 6 and 8 members, respectively. Each of the remaining groups consisted of 2 members only. It was also impossible to group the remaining experts as they didn't show a suffcient level of agrreement with members of previously defined groups.

Results of the identification of groups of experts who share the same opinions about character of problems allowed DEMATEL inventors to indicate the most numeorus groups. Such groups represented a consistent view of world's problem. Therefore it was proposed to name such groups a "school of thoughts". It was ultimately decided that only two large groups deserved to carry such name. Interestingly enough, the identification of two schools of thought found additional justification in radical differences in both represented views on world's problems and a background of school of thought members. That was because one school of thought recognized a hierarchical structure of world's problems and consisted of the representatives of administration and developed part of the world in general while the other favored network structure of inter-related world's problems and gathered repesentatives of less-developed countries, religion, and science.

\subsection{The analysis of indirect influence}

Note that form of direct influence matrix $\mathbf{X}$ which satisfies the condition (3) implies that structure of indirect influence may be expressed by the following formula:

$$
\Delta \mathbf{X}=\mathbf{X}^{2}(\mathbf{I}-\mathbf{X})^{-1} .
$$

Information about indirect influence allowed Fontela and Gabus to propose to enrich their quest for the identification of actual structure of world's problems by the analysis of the processs of shaping a structure of total influence of problems.

\subsection{Extra analysis of total influence}

In addition to the obvious application of indicators $(6,7)$, when analyzing the structure of total influence, DEMATEL inventors also used measures (24-27), similar to $(8-10)$, to determine the total impact of individual problems and total impact of 
other problems on individual problems. The measures looked as follows:

$$
\begin{array}{cc}
\underset{j=1 \ldots n}{\forall} & \sum_{j=1}^{n} t_{i j} ; \\
\underset{j=1 \ldots n}{\forall} & \sum_{j=1}^{n} t_{j i}
\end{array}
$$

in the case of general total influence analysis, and

$$
\begin{array}{cc}
\underset{j=1 \ldots n}{\forall} & \sum_{j=1}^{n} t_{i j}^{(k)} ; \\
\underset{j=1 \ldots n}{\forall} & \sum_{j=1}^{n} t_{j i}^{(k)}
\end{array}
$$

in the case of analysis targeted at opinions of individual experts, where matrices of total influence $\mathbf{T}^{(k)}$ for individual experts resulted from the application of the following formula:

$$
\mathbf{T}^{(k)}=\mathbf{X}^{(k)}\left(\mathbf{I}-\mathbf{X}^{(k)}\right)^{-1},
$$

whose validity depended on the satisfaction of the following condition:

$$
\mathbf{X}^{*(k)} \rightarrow \mathbf{X}^{(k)}: \lim _{m \rightarrow \infty} \mathbf{X}^{(k)^{m}}=\mathbf{0}_{n \times n} .
$$

The indices (24-27) could be utilised for the identification of key problems according to total influence in similar manner like the indices (8-11) could be applied in the case of direct influence.

Another original DEMATEL suggestion was related to the analysis of total influence structure $\mathbf{T}$ (5) towards the identification of possible total influence feedback among problems. The application of special qadratic $n$ by $n$ binary matrix $\mathbf{B}$, analogous to matrix $\mathbf{E}$ (13), was proposed in this regard:

$$
\underset{i, j=1 \ldots n}{\forall} \quad b_{i j}= \begin{cases}1 & \text { for } t_{i j}>0, \\ 0 & \text { otherwise },\end{cases}
$$

whose elements signaled the case of total influence of the $i$-th consecutive problem on the $j$-th consecutive problem $\left(b_{i j}=1\right)$ and a lack of such influence $\left(b_{i j}=0\right)$. The matrix was applied to define a quadratic $n$ by $n$ matrix $\mathbf{C}$, analogous to matrix $\mathbf{F}$ (14):

$$
\mathbf{C}=\mathbf{B}+\mathbf{B}^{\mathrm{T}} .
$$

Matrix $\mathbf{C}$ elements might correspond with a lack of any total infuence $\left(c_{i j}=0\right)$, total influence of one problem on the other one $\left(c_{i j}=1\right)$ or total influence feedback $\left(c_{i j}=2\right)$, in the case of the pair of the $\mathrm{i}$-th consecutive problem and the $\mathrm{j}$-th consecutive problem.
The ultimate proposal based on total influence structure use dealt with the comparison of divisions of problems into causes and effects obtained by different experts. Individual structures of total influence $\mathbf{T}^{(k)}$ (28) were utilised in this regard. The difference between corresponding row-wise sum and column-wise sum of matrix $\mathbf{T}^{(k)}$ elements:

$$
\underset{k, l=1 \ldots K}{\forall} \underset{j=1 \ldots n}{\forall} \sum_{j=1}^{n}\left(t_{i j}^{(k)}-\sum_{j=1}^{n} t_{j i}^{(k)}\right)
$$

was used to identify overall causal $\left(\Delta t^{(k)_{i j}}>0\right)$ or consequent $\left(\Delta t^{(k)}{ }_{i j}<0\right)$ role of the $\mathrm{i}$-th consecutive problem according to the $\mathrm{k}$-th consecutive expert. The experts could be then associated with each other on the basis of sufficient number of concordant opinions about overall character of problems likewise the case of direct influence structure application (see: section 3.1).

\section{Conclusions}

DEMATEL technique is perceived as an established and very popular tool now (Sheng-Li et al., 2018). Howewer, original reports of the inventors of the technique, which contemporary users of the technque are unaware of, show that only a part of original DEMATEL potential is exploited nowadays. This is why original features of the technique, which aren't commonly known, are disclosed in the paper to make them available for the general public, again.

The results of the original application of the technique (Fontela \& Gabus, 1973) are utilized in the paper to unveil the potential behind the disclosed technique features. It turns out that the application of the features may be paricularly useful for the analysis of a character of collective and individual expert opinions and their effects as well as the analysis of a process of the development of total influence structure. The application of the features components not only may help in systematising the analyses and in the informed use of experts' opinions but also facilitates acquiring of extra knowledge about actual features of a considered system. It can be finally concluded, therefore, that the application of disclosed original DEMATEL features may contribute to significant enrichment of the use and extension of application range of the technique.

Finally, it is worth emphasizing the original and source character of the work. This is because of the lack of access for general public to official reports which describe full version of the method and the motivation behind its invention. It may be treated, therefore, as a rare source material that can 
contribute to the spread of full infomed exploitation of DEMATEL technique potential amongst its contemporary users.

\section{Funding}

Publication of the paper was financed by the AGH University of Science and Technology (subject subsidy for maintaining research potential).

\section{References}

Chen, C.-Y., Tzeng, G.-H., \& Huang, J.-J. (2018). Generalized dematel technique with centrality measurements. Technological and Economic Development of Economy, 24(2), 600-614. https://doi.org/10.3846/20294913.2016.1216471

Chiu, Y.-J., Chen, H.-C., Tzeng, G.-H., \& Shyu, J. Z. (2006). Marketing strategy based on customer behaviour for the LCD-TV. International Journal of Management and Decision Making, 7(2-3), 143165. https://doi.org/10.1504/IJMDM.2006.009140

Dytczak, M., \& Ginda, G. (2009). Identification of building repair policy choice criteria role. Technological and Economic Development of Economy, 15(2), 213-228.

https://doi.org/10.3846/1392-8619.2009.15.213-228

Dytczak, M., \& Ginda, G. (2013). Is explicit processing offuzzy direct influence evaluations in DEMATEL indispensable? Expert Systems with Applications, 40(12), 5027-5032.

https://doi.org/10.1016/j.eswa.2013.02.034

Fontela, E. (1974). DEMATEL 1973 Report: analytical methods. Batelle-Geneva.

Fontela, E., \& Gabus, A. (1975). DEMATEL 1974 Report: structural analysis of the world problematique. Batelle-Geneva.

Fontela, E., \& Gabus, A. (1973). World problems: an invitation to futher thought (Technical Report). Batelle-Geneva.

Fukushi, K., \& Narita, Y. (2002). Study on function and failure analysis of snow melting machines. Nippon Kikai Gakkai Ronbunshu, C Hen/Transactions of the Japan Society of Mechanical Engineers, Part $C$, 68(11), 3447-3455. https://doi.org/10.1299/kikaic.68.3447

Furumoto, N., Tabuchi, T., Kiyozumi, R., \& Kobayashi, I. (1998). Analysis of doctor's diagnosis by improved DEMATEL method. Japan Journal of Medical Informatics, 18(3), 205-210.

Gabus, A. (1974). DEMATEL 1973 Report: communication procedure. Batelle-Geneva.

Gabus, A., \& Fontela, E. (1975). DEMATEL 1975 Report: perceptions of the world problematique. Batelle-Geneva.

Gabus, A., \& Fontela, E. (1976). The DEMATEL observer (DEMATEL 1976 Report). Geneva-Batelle.
Hori, S., \& Shimizu, Y. (1999). Designing methods of human interface for supervisory control systems. Control Engineering Practice, 7(11), 1413-1419. https://doi.org/10.1016/S0967-0661(99)00112-4

Jayakrishna, K., Vimal, K. E. K., Vibha, M., Jain, S., \& Kulatunga, A. K. (2020). Fostering systematic ecoinnovation in an industrial symbiosis environment using DEMATEL. International Journal of Industrial and Systems Engineering, 34(1), 20-42. https://doi.org/10.1504/IJISE.2020.104314

Jerry Ho, W.-R., Tsai, C.-L., Tzeng, G.-H., \& Fang, S.K. (2011). Combined DEMATEL technique with a novel MCDM model for exploring portfolio selection based on CAPM. Expert Systems with Applications, 38(1), 16-25. https://doi.org/10.1016/j.eswa.2010.05.058

Kawata, T. (1981). An attempt of multivariate data analysis and Dematel to develop the academic intelligent system. The report of dental education as it ought to be. Shikai Tenbo / Dental Outlook, 57(6), 1327-1333.

Lee, Y.-C., Li, M.-L., Yen, T.-M., \& Huang, T.-H. (2010). Analysis of adopting an integrated decision making trial and evaluation laboratory on a technology acceptance model. Expert Systems with Applications, 37(2), 1745-1754. https://doi.org/10.1016/j.eswa.2009.07.034

Lin, C.-K., Chen, Y.-S., \& Chuang, H.-M. (2016). Improving project risk management by a hybrid MCDM model combining DEMATEL with DANP and VIKOR methods - An example of cloud CRM. In J. Hung, N. Yen, \& K. C. Li. (Eds.), Frontier Computing (Vol. 375, pp. 1033-1040). https://doi.org/10.1007/978-981-10-0539-8_101

Liou, J. J. H., Yen, L., \& Tzeng, G.-H. (2008). Building an effective safety management system for airlines. Journal of Air Transport Management, 14(1), 20-26.

https://doi.org/10.1016/j.jairtraman.2007.10.002

Qu, Y., Lu, Y., \& Li, X. (2015). Operation and maintenance risk analysis for software projects based on DEMATEL method. ICIC Express Letters, Part B: Applications, 6(8), 2259-2265.

Ren, H., Yang, Y., \& Masayuki, K. (2001). Analysis of the influencing factors on the contract hire system for agricultural machines in Thailand. Nongye Jixie Xuebao/Transactions of the Chinese Society of Agricultural Machinery, 32(4), 105-108.

Sheng-Li, S., Xiao-Yue, Y., Hu-Chen, L., \& Ping, Z. (2018). DEMATEL technique: a systematic review of the state-of-the-art literature on methodologies and applications. Mathematical Problems in Engineering, 2018, 3696457. https://doi.org/10.1155/2018/3696457

Tamura, H., \& Akazawa, K. (2005). Structural modeling of uneasy factors under uncertainty. In Proceedings of the SICE Annual Conference (pp. 3180-3185). 
Tan, W.-K., \& Kuo, C.-Y. (2014). Prioritization of facilitation strategies of park and recreation agencies through DEMATEL analysis. Asia Pacific Journal of Tourism Research, 19(8), 859-875. https://doi.org/10.1080/10941665.2013.812570

Torbacki, W., \& Kijewska, K. (2019). Identifying key performance indicators to be used in logistics 4.0 and industry 4.0 for the needs of sustainable municipal logistics by means of the DEMATEL method. Transportation Research Procedia, 39, 534-543. https://doi.org/10.1016/j.trpro.2019.06.055

Wu, W.-W., Lan, L. W., \& Lee, Y.-T. (2012). Exploring decisive factors affecting an organization's SaaS adoption: A case study. International Journal of Information Management, 31(6), 556-563. https://doi.org/10.1016/j.ijinfomgt.2011.02.007

Wu, W.-W., \& Lee, Y.-T. (2007). Developing global managers' competencies using the fuzzy DEMATEL method. Expert Systems with Applications, 32(2), 499-507. https://doi.org/10.1016/j.eswa.2005.12.005

Zhou, X., Shi, Y., Deng, X., \& Deng, Y. (2017). DDEMATEL: A new method to identify critical success factors in emergency management. Safety Science, 91, 93-104. https://doi.org/10.1016/j.ssci.2016.06.014 